\title{
Adsorption of As (III) and As (V) from aqueous solution by modified Cassia fistula (golden shower) biochar
}

\author{
Md. Arsh Alam ${ }^{1}$. Wasim Akram Shaikh ${ }^{1} \cdot$ Md. Osaid Alam ${ }^{1} \cdot$ Tanushree Bhattacharya $^{1} \cdot$ Sukalyan Chakraborty ${ }^{1}$. \\ Bibhutibhushan Show ${ }^{2} \cdot$ Indranil Saha ${ }^{3}$
}

Received: 25 November 2016 / Accepted: 1 October 2018 / Published online: 15 October 2018

(c) The Author(s) 2018

\begin{abstract}
The biosorption of two Arsenic (As) species [As (III) and As (V)] from aqueous solution onto activated biochar derived from Cassia fistula, belonging to Fabaceae family was studied. SEM/EDX characterization of the adsorbent showed an irregular, porous, and heterogeneous surface morphology with calcium and iron available for As binding. FTIR also showed the presence of groups responsible for As adsorption. Batch adsorption experiments were conducted to determine the optimum conditions for As adsorption to the biomass with optimum adsorbent dose, ambient temperature, initial concentration of As, $\mathrm{pH}$, and stirring rate. Under optimized conditions, the maximum removal percentage was $78.1 \%$ [uptake capacity $\left(q_{\mathrm{e}}\right)=0.78 \mathrm{mg} / \mathrm{g}$ ] for As (III) and $84.8 \%$ [uptake capacity $\left(q_{\mathrm{e}}\right)=0.42 \mathrm{mg} / \mathrm{g}$ ] for As $(\mathrm{V})$. The Freundlich isotherm model, characteristic of multilayer binding, fit the data best with $R^{2}$ values of 0.92 for As (III) and 0.96 for As (V). Fitting of the data to the Dubinin-Radushkevich model indicated physisorption, while the kinetics study suggested a pseudo-second-order reaction. Thermodynamic parameters indicated adsorption was spontaneous. In aqueous solutions, phosphate hindered As removal more than the any other ions. Regeneration studies showed a $23.0 \%$ and $21.1 \%$ recovery for arsenite and arsenate, respectively, indicating limited leaching under both acidic and alkaline conditions. The absorptive capacity of $C$. fistula biomass for arsenic removal was compared with a number of other reported biosorbents and was found to be considerably efficient.
\end{abstract}

Keywords Arsenic $\cdot$ Biosorption $\cdot$ Cassia fistula $\cdot$ Equilibrium $\cdot$ Thermodynamics $\cdot$ Kinetics

Sukalyan Chakraborty

sukalyanchakraborty@bitmesra.ac.in

Md. Arsh Alam

arshalam0@gmail.com

Wasim Akram Shaikh

wasim.bu12@gmail.com

Md. Osaid Alam

osaid2k9@gmail.com

Tanushree Bhattacharya

tbhattacharya@bitmesra.ac.in

Bibhutibhushan Show

bibhutishow1978@gmail.com

Indranil Saha

indranilsaha2010@yahoo.com

1 Department of Civil and Environmental Engineering, Birla Institute of Technology, Mesra, Ranchi, Jharkhand 835215, India

2 Department of Chemistry, Jadavpur University, Kolkata, West Bengal 700032, India

3 Department of Chemistry, Sripat Singh College, Jiaganj, Murshidabad, West Bengal 742123, India

\section{Introduction}

Arsenic (As) is a toxic and non-degradable metalloid present in the environment in both the organic (i.e., monomethyl arsenate-MMA, dimethyl arsenate-DMA) and inorganic (i.e., arsenite, arsenious acid, arsenate, and arsenic acid) forms (Kumaresan and Riyazuddin 2001). For inorganic As, four main oxidation states commonly exist: $\mathrm{As}^{-3}$ (arsine), $\mathrm{As}^{0}$ (elemental arsenic), $\mathrm{As}^{+3}$ (arsenite), and $\mathrm{As}^{+5}$ (Arsenate). As contamination of the environment is a matter of concern since As accumulates in environment and enters the food chain through drinking water and crops (Chakraborty et al. 2014; Alam et al. 2016). The main sources of As groundwater contamination can be both natural and anthropogenic (ref). Naturally As enters groundwater via leaching, rock weathering, volcanic eruption, geochemical reaction, and biological activity (Kanel et al. 2005a, b). Common anthropogenic As sources include timber treatment with copper chrome arsenate, fertilizers from agriculture sources, and a variety of pharmaceutical, glass, and other chemical 
activities. As contamination of groundwater has caused havoc in over 70 countries of the world affecting around 150 million people (Ravenscroft et al. 2009). In Bangladesh and India alone, 70 million people are at risk, due to exposure to high concentrations of As in drinking water (Niu et al. 2007). Several diseases like dysfunction of the respiratory system, injury to the nervous system, hepatomegaly, hypertension, and diseases of the peripheral vascular and cardiovascular system with lungs, kidney, liver, skin, large intestine, buccal cavity, urinary track, bone rectum cancer has been reported from this region (Guan et al. 2012). Due to such increasing effect of As, WHO has set permissible limit of As in drinking water as $10 \mu \mathrm{g} / \mathrm{L}$ (WHO 1993).

Consequently, a significant amount of As remediation research has been conducted over the last few decades and various techniques proposed as potential remedial options including coagulation, chemical precipitation, iron co-precipitation, ion-exchange, reverse osmosis, and ultrafiltration. However, many of the proposed techniques have significant disadvantages, e.g., high cost, huge energy requirements, and incomplete removal of As which have hindered their acceptability (Choong et al. 2007). Today, simple adsorption remains the most efficient technique for removal of aqueous As owing to its cost-effectiveness, environment friendliness, (Zhang et al. 2003), ability for adsorbent regeneration, and sludge-free operation (Ranjan et al. 2009). Various different adsorbents have been used for the removal of As from aqueous solutions including activated alumina (Kunzru and Chaudhuri 2005), activated carbon (Chuang et al. 2005a, b), feldspar, and metal-loaded limestone (Ohki et al. 1996), goethite (Gimenez et al. 2007), hematite (Mamindy-Pajany et al. 2009), hydrous zirconium oxide (Bortun et al. 2010), and magnetite. However, most of these adsorbents are costly and inefficient (Volesky 2001), and the field is constantly in search of cheap and efficient adsorbents. Biomaterial is one of the most appropriate materials for As removal from aqueous solution (Chomchoey et al. 2013), and consequently, biosorption development has gained increased popularity due to its ecofriendly nature, excellent performance, and cost-effectiveness for remediation of heavily metal-loaded water (Volesky 2001). Various biomaterials have been proposed like animal biopolymer (Ishikawa et al. 2004), Aspergillus niger biomass (Pokhrel and Viraraghavan 2007), crab shells (Niu et al. 2007), heat-resistant fungi (erÁansky et al. 2007), lignocellulosic substrate loaded with ferric ion (Dupont et al. 2007), and powdered eggshell (Oke et al. 2008).

In the present study, Cassia fistula was used as a biosorbent to remove As (III) and As (V) from aqueous solution. $C$. fistula, commonly known as Golden shower, is a fast-growing medium-sized deciduous tree belonging to fabales order, of the Fabaceae family. C. fistula which bears yellow flowers and has seeds, which are encased in cylindrical shaped pods, has been shown to have a high potential as a heavy metal biosorbent (Hanif et al. 2007) with up to $90 \%$ removal of $\mathrm{Ni}$ from an industrial wastewater (Hanif et al. 2007). An even higher removal rate (100\%) for $\mathrm{Ni}$ (II) by C. fistula was observed with an initial concentration of $25 \mathrm{mg} / \mathrm{L}$. Hanif et al. (2007) stated that the increased binding capacity for metal during adsorption by $C$. fistula was due to the significant number of ionizable groups available for binding such as carboxyl, carbonyl, alcoholic, and amino groups. Both $\mathrm{Cr}$ (III) and $\mathrm{Cr}$ (VI) were also found to be sorbed from aqueous solution by a C. fistula biomass (Abbas et al. 2008). In the present study, $C$. fistula pods were tested for their capacity to remove arsenate and arsenite from the aqueous solution along with optimization of factors like initial concentration of As (III) and As (V), contact time, stirring rate, temperature, adsorbent dose, and $\mathrm{pH}$ of the solution to achieve the best performance conditions through batch experiments.

\section{Materials and method}

\section{Reagents and apparatus}

All chemicals were analytical grade (Merck India Ltd.) and used without further purification. Prior to use all the glassware was acid washed $\left(15 \% \mathrm{HNO}_{3}\right)$, rinsed with double-distilled water and oven dried. All the reagents were prepared using double-distilled water, and the $\mathrm{pH}$ was maintained using either $0.1 \mathrm{M} \mathrm{HCl}$ or $0.1 \mathrm{M} \mathrm{NaOH}$.

\section{Instrumentation}

Arsenic [As (III) and As (V)] solution concentrations were determined by inductively coupled plasma optical emission spectrophotometer (ICP-OES) (PerkinElmer, USA; Optical 2100DV). $\mathrm{pH}$ was measured using a YSI multiparameter (YSI Professional Plus model 6,050,000). SEM coupled with EDX (Jeol, Japan, JSM-6390LV) was used to study adsorbent surface characteristics. FTIR (Shimadzu Corporation, Japan, IR-Prestige 21) analysis was also undertaken to investigate internal binding of As [As (III) and As (V)] by the adsorbent, and XRD of the adsorbent was carried out using Bruker D8 advance X-ray diffractometer. The X-ray diffraction (XRD) technique using Bruker D8 advance X-ray diffractometer with Bragg-Brentano goniometer geometry and $\mathrm{Cu}-\mathrm{K}_{\alpha} \mathrm{X}$-radiation source $(\lambda=1.5418 \AA)$.

\section{Adsorbent collection and preparation}

Pods of $C$. fistula were collected from the Ranchi district of Jharkhand, India. The pod's bark was manually removed and washed thrice with tap water followed by distilled 
water and dried in an oven at $60{ }^{\circ} \mathrm{C}$ to constant weight. The dried biomass was ground to a fine powder $(<250 \mu \mathrm{m})$ which was used for all further processes since the smaller particle size was known to have a greater surface area per unit mass (Markovski et al. 2014). A 100-g portion of the adsorbent was treated with $500 \mathrm{~mL} \mathrm{FeCl}_{3}(0.1 \mathrm{M})$ in $1: 5$ $\mathrm{w} / \mathrm{v}$ ratio, with constant agitation in a shaker for $24 \mathrm{~h}$. at 300 RPM for complete mixing. After shaking the chemically, treated adsorbent was washed thrice by deionized water and neutral $\mathrm{pH}$ was maintained. Further the adsorbent was dried in an oven at $60{ }^{\circ} \mathrm{C}$ for complete removal of moisture and stored in a desiccator for further use. The adsorbent was then thermally activated at $200{ }^{\circ} \mathrm{C}$ for $1 \mathrm{~h}$ in a muffle furnace for the formation of complete biochar (Tan et al. 2016; Chammui et al. 2014) and used for batch experiments using sodium arsenite $\left(\mathrm{NaAsO}_{2}\right)$ and sodium hydrogen arsenate $\left(\mathrm{Na}_{2} \mathrm{HAsO}_{4} \cdot 7 \mathrm{H}_{2} \mathrm{O}\right)$ as synthetic arsenite and arsenate solutions, respectively.

\section{Characterization of adsorbent}

Surface morphology and elemental composition of the dried biomass $(<250 \mu \mathrm{m})$ were characterized by SEM/EDX. FTIR was used to determine the presence of surface functional groups. The point of zero charge of the adsorbent was estimated using the method of Mondal (2010) by recording charge variation with the $\mathrm{pH}$ of the adsorbent mixture. XRD was used to identify the form and phases of iron present.

\section{Experimental setup}

A known mass of adsorbent (1-8 g/L) was added to a synthetic As solution of known concentration $(0.5-5 \mathrm{mg} / \mathrm{L})$ and constantly stirred (100-450 RPM) under nitrogen for defined contact times (10-90 min). After contact, aqueous samples were filtered (pore size $42 \mu \mathrm{m}$ ) and residual As in solution was determined via inductive coupled plasma optical emission spectrometer (ICP-OES). Several different batch experiments were performed using a range of different experimental variables including initial metal concentration $(0.5-5 \mathrm{mg} / \mathrm{L})$, stirring rate (100-450 RPM), contact time (10-90 $\mathrm{min}$ ), $\mathrm{pH} 1-10$, adsorbent dose (1-8 g/L), and temperature $\left(27-80{ }^{\circ} \mathrm{C}\right)$. The biosorption percentage was calculated using:

Biosorption $(\%)=\left(C_{0}-C_{i} / C_{0}\right) \times 100$

where $C_{0}$ is initial metal concentration and $C_{i}$ is measured final soluble metal concentration in solution.

The order and nature of the reaction was identified via kinetic studies and fitting the adsorption data to Langmuir, Freundlich, and Dubinin-Radushkevich isotherm models.

\section{Desorption study and effect of coexisting ions}

After conducting batch adsorption studies the As [As (III) and As (V)] loaded adsorbent was subsequently regenerated by extraction with $25 \mathrm{~mL}$ of $(0.01 \mathrm{M}) \mathrm{NaOH},(0.01 \mathrm{M})$ $\mathrm{HNO}_{3}$, and $(0.1 \mathrm{M})$ EDTA separately by continuous stirring for $30 \mathrm{~min}$ at $55^{\circ} \mathrm{C}$. (Buj`náková et al. 2013). Subsequently, the desorbed concentration of As was determined, and the desorption efficiencies calculated from the amount of total arsenic in the supernatant. The effect of co-ions (i.e., bicarbonate, carbonate, phosphate and sulfate ions prepared using sodium bicarbonate, calcium carbonate, sodium phosphate, and ferrous sulfate salts) as interference on the absorption process was studied at three different concentrations viz. $1 \mathrm{mg} / \mathrm{L}, 5 \mathrm{mg} / \mathrm{L}$ and $10 \mathrm{mg} / \mathrm{L}$ (Mandal et al. 2013).

\section{Result and discussion}

\section{Characterization of adsorbent}

\section{$\mathrm{pH}_{\mathrm{zpc}}$ (zero-point charge of adsorbent)}

The $\mathrm{pH}$ of the adsorbent was found to be slightly less than its $\mathrm{pH}_{\mathrm{zpc}}$ implying surface positive charge due to availability of $\mathrm{H}^{+}$ions. Normally anions would be attracted to such positive adsorbent surface charge (Bhaumik et al. 2012; Fig. 1).

\section{SEM/EDX}

SEM revealed that the adsorbent surface morphology was irregular, porous, and heterogeneous at both $100 \times$ (Fig. 2a) and $1000 \times$ (Fig. 2b). Pores and large cavities could be clearly seen at $3000 \times($ Fig. $2 c)$. Heterogeneity of

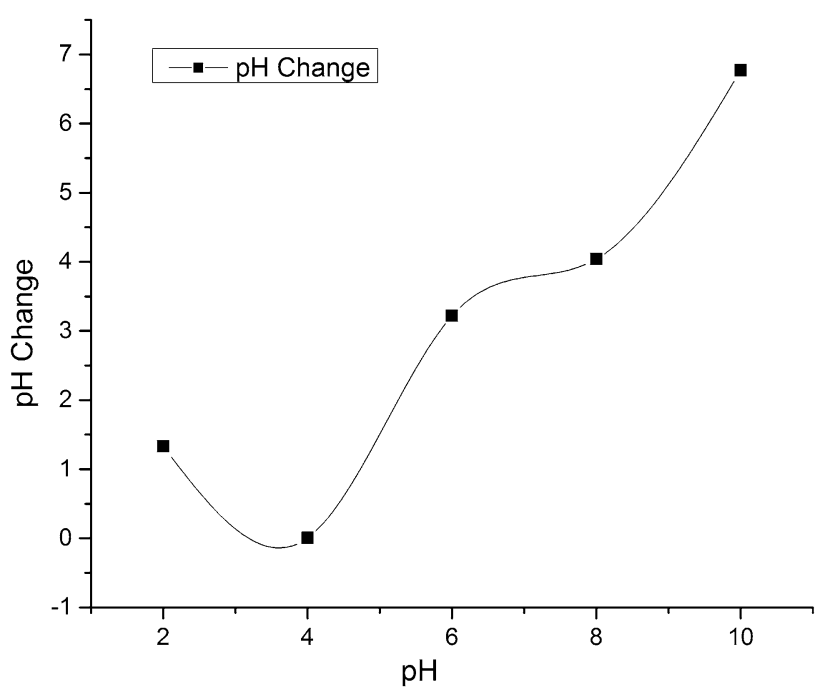

Fig. $1 \mathrm{pH}_{\mathrm{zpc}}$ of the adsorbent 

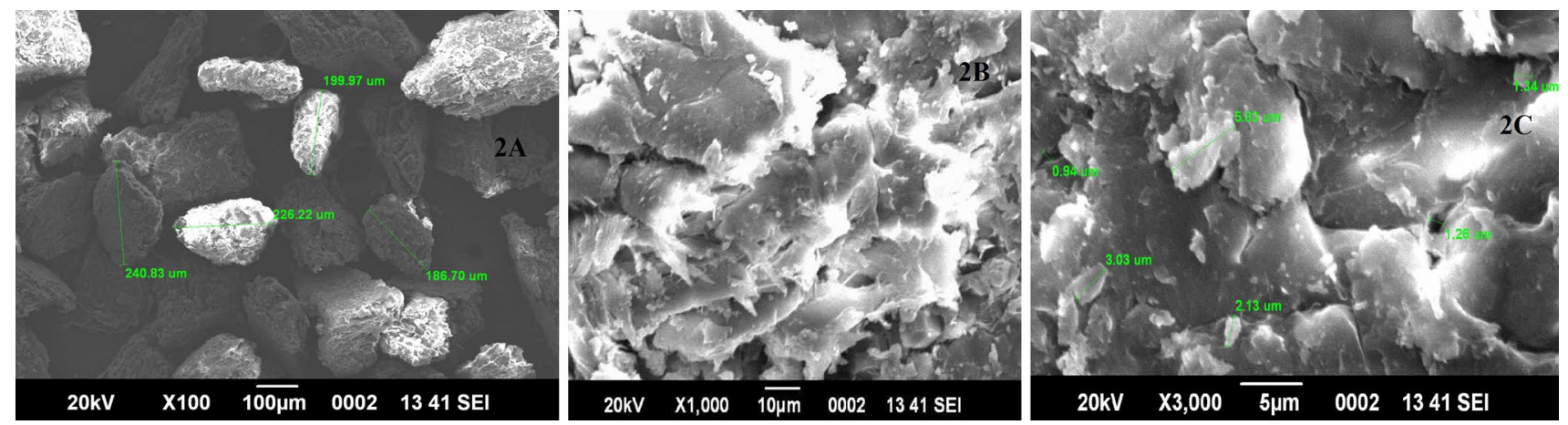

Fig. 2 a Image of SEM at 100×, b image of SEM at 1000 $\times$ and $\mathbf{c}$ image of SEM at 3000×

the adsorbent and the cavities indicate their greater adsorption ability due to their extended surface area (Chowdhury et al. 2011). The elemental composition of the adsorbent's surface determined by EDX (Paul et al. 2012) showed the presence of $\mathrm{Ca}$ and $\mathrm{Fe}$ (Fig. 3a), known to be effective binding agents. EDX result after adsorption showed significant peaks of arsenic (Fig. 3b, c) confirming uptake of both (As (III) and As (V)) on to the surface of the adsorbent.

\section{FTIR}

FTIR analysis before and after adsorption (Fig. 4) showed major difference in the regions $2800-3400 \mathrm{~cm}^{-1}$ and $850-1750 \mathrm{~cm}^{-1}$ indicating binding of As species with adsorbent. The peak originally at $3329 \mathrm{~cm}^{-1}$ which is commonly associated with As (III) was shifted to $3287 \mathrm{~cm}^{-1}$ and $3264 \mathrm{~cm}^{-1}$ suggesting involvement of $\mathrm{N}-\mathrm{H}$ amino (stretch) group. At the same time, the peak at $1597 \mathrm{~cm}^{-1}$ was shifted to $1590 \mathrm{~cm}^{-1}$ indicating involvement of $\mathrm{N}-\mathrm{H}$ amino (bending) group. In addition peaks attributable to $\mathrm{C}-\mathrm{H}$ stretch $\left(2916 \mathrm{~cm}^{-1}\right), \mathrm{C}=\mathrm{O}$ stretch $\left(1736 \mathrm{~cm}^{-1}\right),-\mathrm{C}=\mathrm{O}$ stretch $\left(1508 \mathrm{~cm}^{-1}\right), \mathrm{C}-\mathrm{O}$ aloxy $\left(1238 \mathrm{~cm}^{-1}\right)$, and $\mathrm{C}-\mathrm{H}$ alkene $\left(899 \mathrm{~cm}^{-1}\right)$ were shifted to $2901 \mathrm{~cm}^{-1}, 1724 \mathrm{~cm}^{-1}$ for As (III) $1728 \mathrm{~cm}^{-1}$ for As (V), $1512 \mathrm{~cm}^{-1}, 1246 \mathrm{~cm}^{-1}$ for As (III), and $1231 \mathrm{~cm}^{-1}$ for As (V) and $895 \mathrm{~cm}^{-1}$ for As (III), respectively, which indicates that these functional group are mainly responsible for binding of As via adsorbent.

\section{XRD}

The $C$. fistula derived adsorbent showed two distinctive peak at around $2 \theta=15.95^{\circ}$ and $22.54^{\circ}$. The absence of sharp peaks indicated an amorphous nature and porosity. From the XRD analysis, the position of the diffracted peaks is almost same with the previously reported peak positions of $C$. fistula Pod. The amorphous crystalline structure of $C$. fistula Pod serves good adsorbivity toward arsenic ions (Sorokhaibam et al. 2015). The X-ray patterns of the adsorbent before and after As (III) and As (V) were slightly different (Fig. 5).
It is expected that the amorphous nature of the adsorbent surface will decrease as toxic metal ions are adsorbed causing a direct increase in the intensity of diffraction peaks (Senniappan et al. 2017; Lesmana et al. 2009). Comparison of the XRD traces for the activated adsorbent material before adsorption $\left(\mathrm{Ad}_{1}\right)$ and after As adsorption $\left(\mathrm{Ad}_{2}\right.$ and $\left.\mathrm{Ad}_{3}\right)$ indicates the presence of pure iron oxides $\left(\gamma-\mathrm{Fe}_{2} \mathrm{O}_{3}\right)$ having $2 \theta=29.45^{\circ}$ and $35.97^{\circ}$ involved in the biosorption of As (III) and As (V) through complexation and chelation reactions, resulting in low-intensity peaks of different iron oxides phases, i.e., lepidocrocite $(\gamma-\mathrm{FeOOH})$ and magnetite/maghemite $\left(\mathrm{Fe}_{3} \mathrm{O}_{4} / \gamma-\mathrm{Fe}_{2} \mathrm{O}_{3}\right)$. In the present study, the peaks were found to slowly decaying, when the adsorbate was treated with As solution up to $5 \mathrm{mg} / \mathrm{L}$ (Fu et al. 2011; Du et al. 2013).

\section{Batch operation and effect of operating parameters on removal efficiency}

\section{Initial concentration}

The effect of initial As concentration on removal efficiency of the adsorbent was studied by varying the initial As concentration from 0.5 to $5 \mathrm{mg} / \mathrm{L}$ while maintaining all other

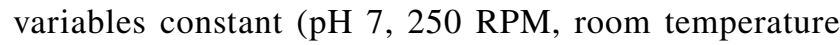
$\left(27^{\circ} \mathrm{C}\right), 30$ min contact time and a $4 \mathrm{~g} / \mathrm{L}$ adsorbent dose). Overall, irrespective of the As species used, increasing the initial concentration initially led to increase in the As removal percentage and reached an optimum level of $70.5 \%$ (uptake capacity $\left(q_{\mathrm{e}}\right)=0.71 \mathrm{mg} / \mathrm{g}$ ) for As (III) at an initial concentration of $2 \mathrm{mg} / \mathrm{L}$ and $78.9 \%\left(q_{\mathrm{e}}=0.39 \mathrm{mg} / \mathrm{g}\right)$ for As (V) at an initial concentration of $4 \mathrm{mg} / \mathrm{L}$ (Fig. 6a, b).This happens due to decrease in resistance capacity of metal in aqueous solution and availability of more active binding sites to (As (III) and As (V)) ions at the initial phase of the reaction at a fixed adsorbent dose (Suresh et al. 2012). But thereafter progressive saturation of the active binding sites on the adsorbent occurs with simultaneous decline in 
Fig. 3 a Image of EDX before adsorption, $\mathbf{b}$ and $\mathbf{c}$ image of EDX after adsorption of arsenite and arsenate respectively

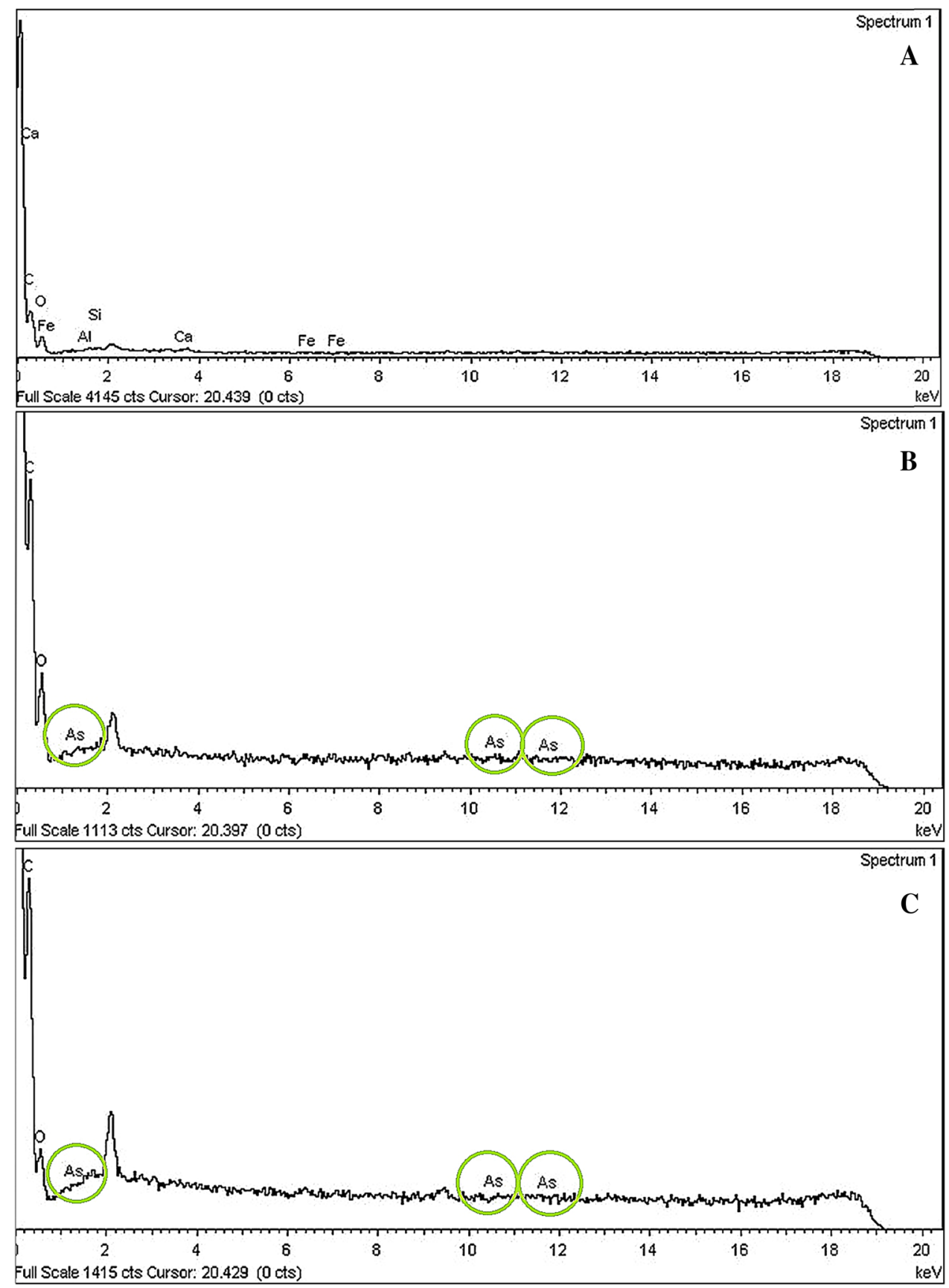

removal percentage. (Tsai and Chen 2010). Similar trend has been reported by Roy et al. (2013) for arsenic removal.

\section{Contact time}

Contact time was varied from 10 to 90 min using initial concentration of $4 \mathrm{mg} / \mathrm{L}$ for arsenite and $2 \mathrm{mg} / \mathrm{L}$ for arsenate. For both As species the percent removal increased up to $40 \mathrm{~min}$ reaching $72.6 \%\left(q_{\mathrm{e}}=0.73 \mathrm{mg} / \mathrm{g}\right)$ and $79.2 \%$ $\left(q_{\mathrm{e}}=0.40 \mathrm{mg} / \mathrm{g}\right)$ for arsenite and arsenate, respectively.
Thereafter, the removal percentage decreased for both species over the next 50 min (Fig. 7a, b). The initial rapid uptake of As suggests that removal efficiency is increasing with time simply due to increased availability of active binding sites on the surface of the adsorbent (Das and Mondal 2011). However, after about $40 \mathrm{~min}$, the removal percentage did not increase further which might be due repulsion between solute molecules on the surface of the adsorbent (Roy et al. 2013). 


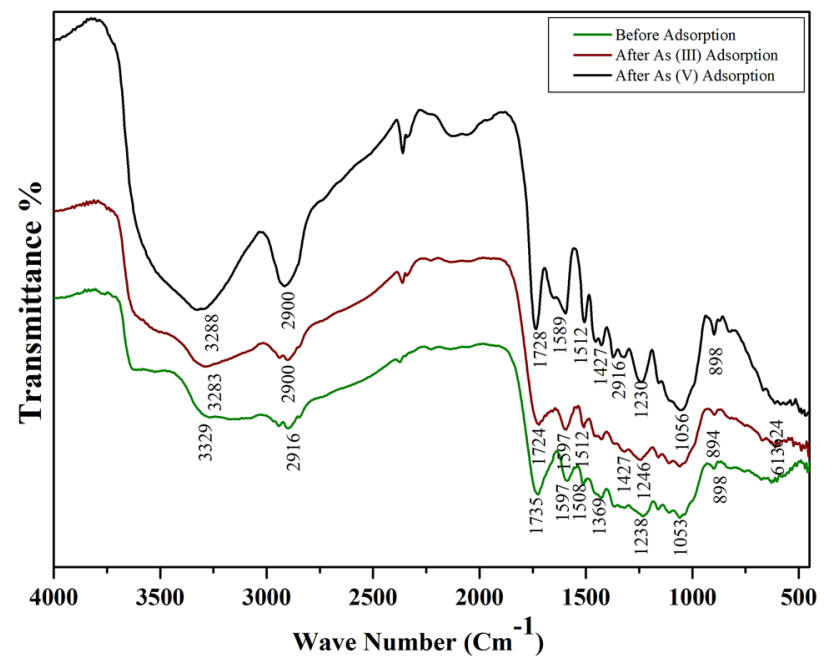

Fig. 4 FTIR image before and after adsorption of arsenite and arsenate respectively

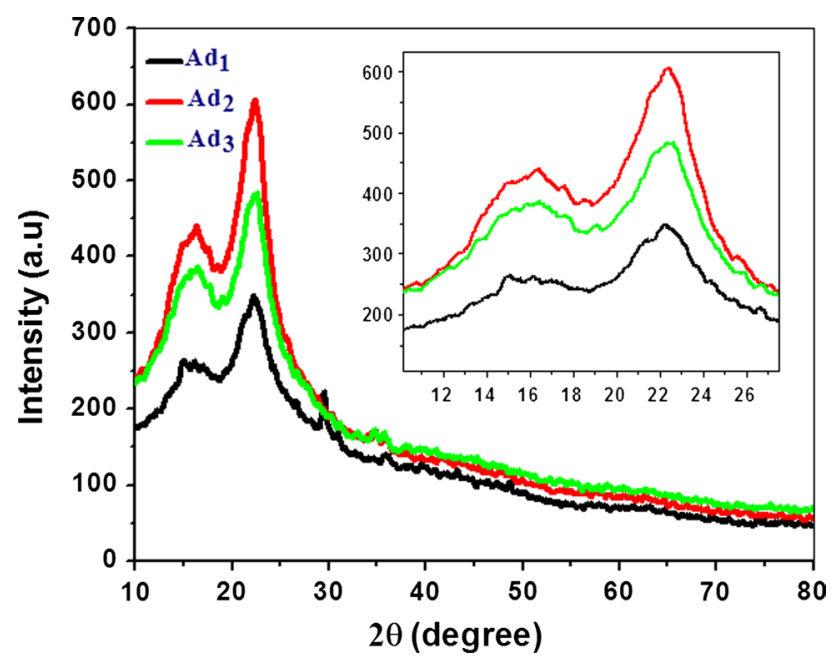

Fig. 5 XRD image of the adsorbent [before $\left(\operatorname{Ad}_{1}\right)$ after adsorption of arsenite $\left(\mathrm{Ad}_{2}\right)$ and arsenate $\left.\left(\mathrm{Ad}_{3}\right)\right]$

\section{Adsorbent dose}

Adsorbent dose is one of the most important parameters influencing the removal efficiency of an adsorbent. Adsorbent dose was varied from 1 to $8 \mathrm{~g} / \mathrm{L}$ for both As species (As (III) and As (V)) using batch experiments with the optimized initial concentration. Initially removal efficiency increased with increasing adsorbent dose up to $6 \mathrm{~g} / \mathrm{L}$ for arsenite $\left(74.5 \%, q_{\mathrm{e}}=0.75 \mathrm{mg} / \mathrm{g}\right)$ and up to $4 \mathrm{~g} / \mathrm{L}$ for arsenate $\left(79.6 \%, q_{\mathrm{e}}=0.40 \mathrm{mg} / \mathrm{g}\right)$. This increase mainly occurs due to the corresponding increase in active surface binding sites for a given amount of soluble As as the amount of adsorbent increases (Das and Mondal 2011). However, eventually, there is no further increase in removal efficiency regardless of the amount of adsorbent added (Fig. 8a, b). The finite limit in uptake capacity is related to the probable formation of agglomeration and clusters between adsorbent particles at high adsorbent concentrations which consequently limits the number of binding sites available by reducing the adsorbents overall effectively surface area (Fan et al. 2003).

\section{Stirring rate}

Using optimized batch equilibrium conditions, the rate of stirring was varied from 100 to 450 RPM while maintaining all other conditions constant. Removal efficiency initially increased with increasing stirring rate up to 400 RPM $\left(75.0 \%, q_{\mathrm{e}}=0.75 \mathrm{mg} / \mathrm{g}\right)$ for arsenite and up to $350 \mathrm{RPM}$ $\left(78.6 \%, q_{\mathrm{e}}=0.40 \mathrm{mg} / \mathrm{g}\right.$ ) for arsenate (Fig. 9a, b). This was due to efficient utilization of all active binding sites. But thereafter, further increase in stirring rate reduced effective interaction between the adsorbate and binding sites along with disassociation of previously bounded ions. Hence removal efficiency did not increase markedly at higher stirring rates (Roy et al. 2013; Kanwal et al. 2012).

\section{Temperature}

Using the previously optimized parameters, batch equilibrium studies were conducted at $\mathrm{pH} 7$ while the temperature was varied between 27 and $80{ }^{\circ} \mathrm{C}$ (Fig. 10). The maximum removal efficiency was observed at room temperature $\left(27^{\circ} \mathrm{C}\right)$ being $74.7 \%\left(q_{\mathrm{e}}=0.75 \mathrm{mg} / \mathrm{g}\right)$ for arsenite (Fig. 10a) and $78.8 \%\left(q_{\mathrm{e}}=0.40 \mathrm{mg} / \mathrm{g}\right)$ for arsenate (Fig. 10b). Above room temperature, removal efficiency gradually decreased linearly with increasing temperature. This suggested that adsorption was an exothermic in nature and that as temperature increased metals would be increasingly detached/separated from adsorbent surface (Ahmet and Mustafa 2010).

\section{$\mathrm{pH}$}

The $\mathrm{pH}$ is one of the most important parameters controlling metalloid speciation and consequently metalloid sorption. The $\mathrm{pH}$ was varied from 2 to 10 while maintaining other parameters at their optimized levels. The maximum removal efficiency was observed at $\mathrm{pH} 6$ for arsenite $\left(78.1 \%, q_{\mathrm{e}}=0.78 \mathrm{mg} / \mathrm{g}\right)$ and at $\mathrm{pH} 2$ for arsenate $(84.8 \%$, $q_{\mathrm{e}}=0.42 \mathrm{mg} / \mathrm{g}$ ) (Fig. 11). Changes in $\mathrm{pH}$ can significantly alter both the overall surface charge of the adsorbent and specifically the charges of functional groups on the adsorbents surface as well as change the ionization and species of adsorbates. Schiewer and Volesky (2000) observed that at low $\mathrm{pH}$ anionic species were adsorbed more due to availability of $\mathrm{H}^{+}$ions than at higher $\mathrm{pH}$ where cationic species adsorb more due to availability of $-\mathrm{OH}$ ions. 

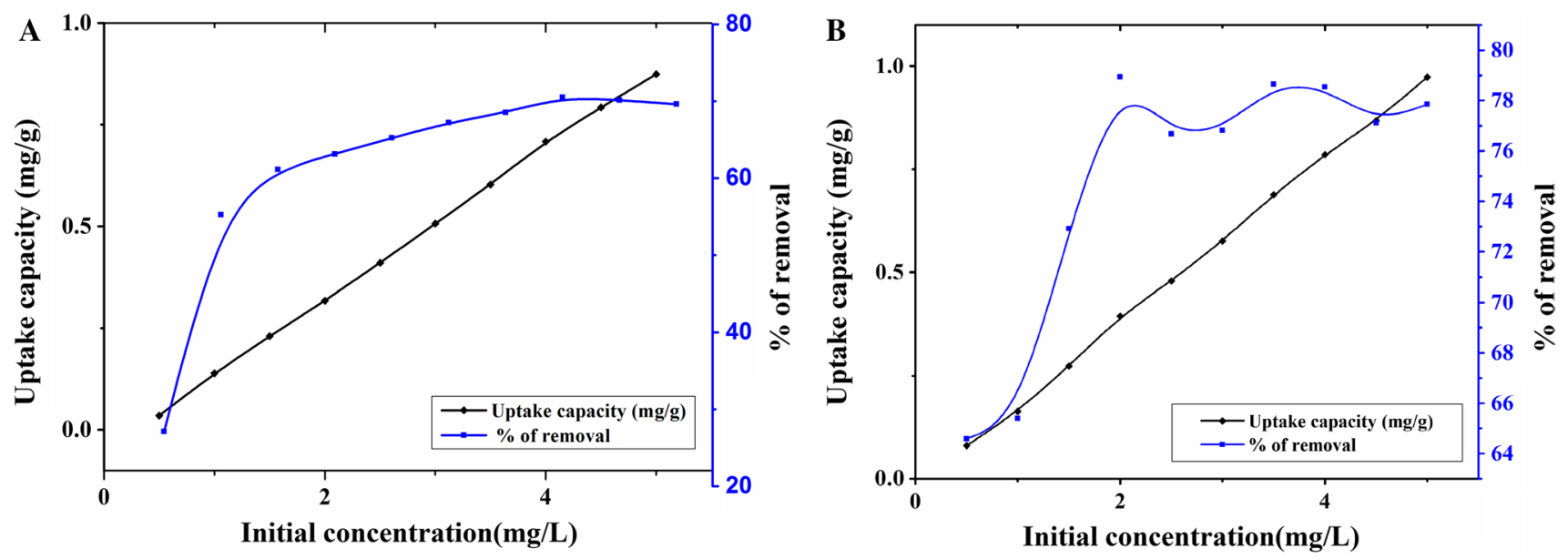

Fig. 6 a and $\mathbf{b}$ effect of initial concentration ranging from 0.5 to $5 \mathrm{mg} / \mathrm{L}$ at $7 \mathrm{pH}, 300 \mathrm{RPM}$, room temperature (300 K), $30 \mathrm{~min}$ and $4 \mathrm{~g} / \mathrm{L}$ of adsorbent dose for arsenite and arsenate, respectively
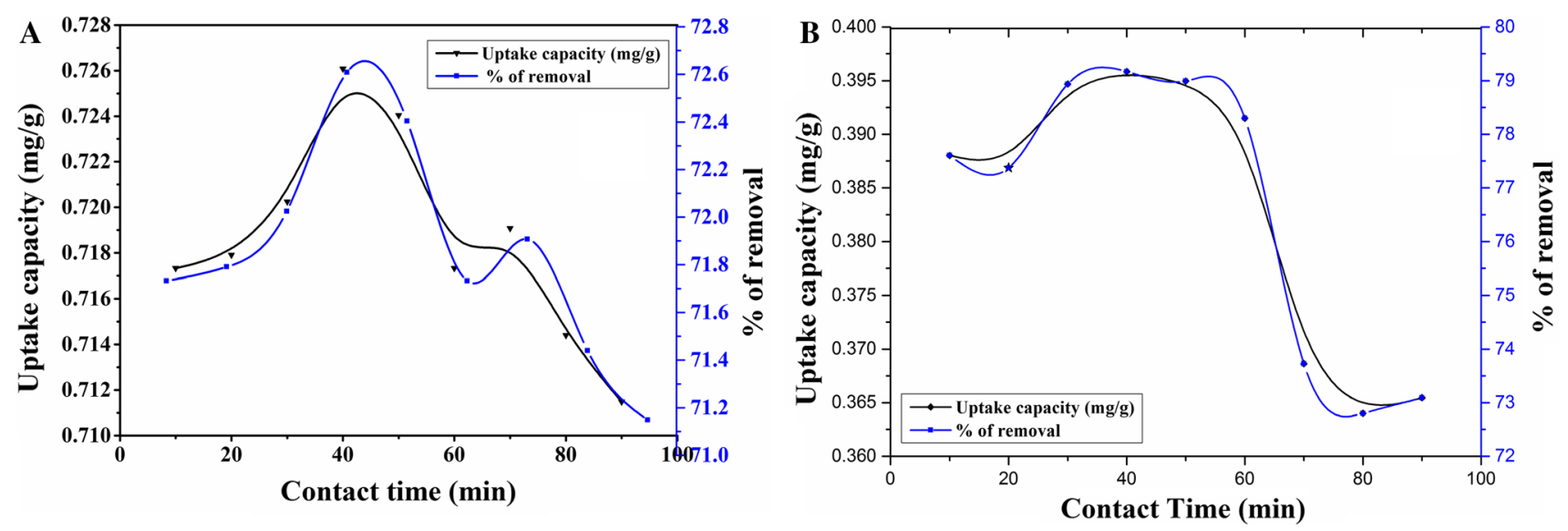

Fig. 7 Effect of contact time for arsenite (a) and arsenate (b) at 7 pH, 4 g/L adsorbent dose, $300 \mathrm{RPM}$ stirring rate, $300 \mathrm{~K}$ temp and initial concentration $4 \mathrm{mg} / \mathrm{L}$ for arsenite and $2 \mathrm{mg} / \mathrm{L}$ for arsenate
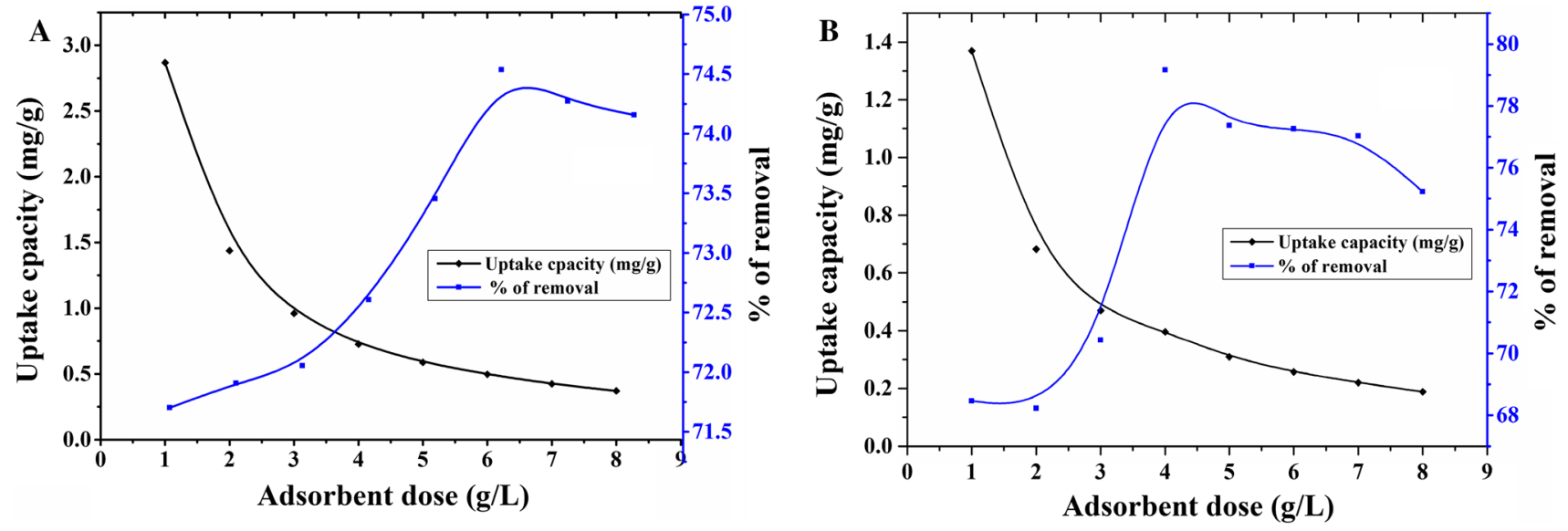

Fig. 8 Effect of adsorbent dose for arsenite (a) at 7 pH, $250 \mathrm{RPM}$ stirring rate, $300 \mathrm{~K}$ temp, $4 \mathrm{mg} / \mathrm{L}$ initial concentration and $40 \mathrm{~min}$. For arsenate (b) at $7 \mathrm{pH}, 300 \mathrm{RPM}$ stirring rate, $300 \mathrm{~K}$ temp, $2 \mathrm{mg} / \mathrm{L}$ initial concentration and $40 \mathrm{~min}$ 

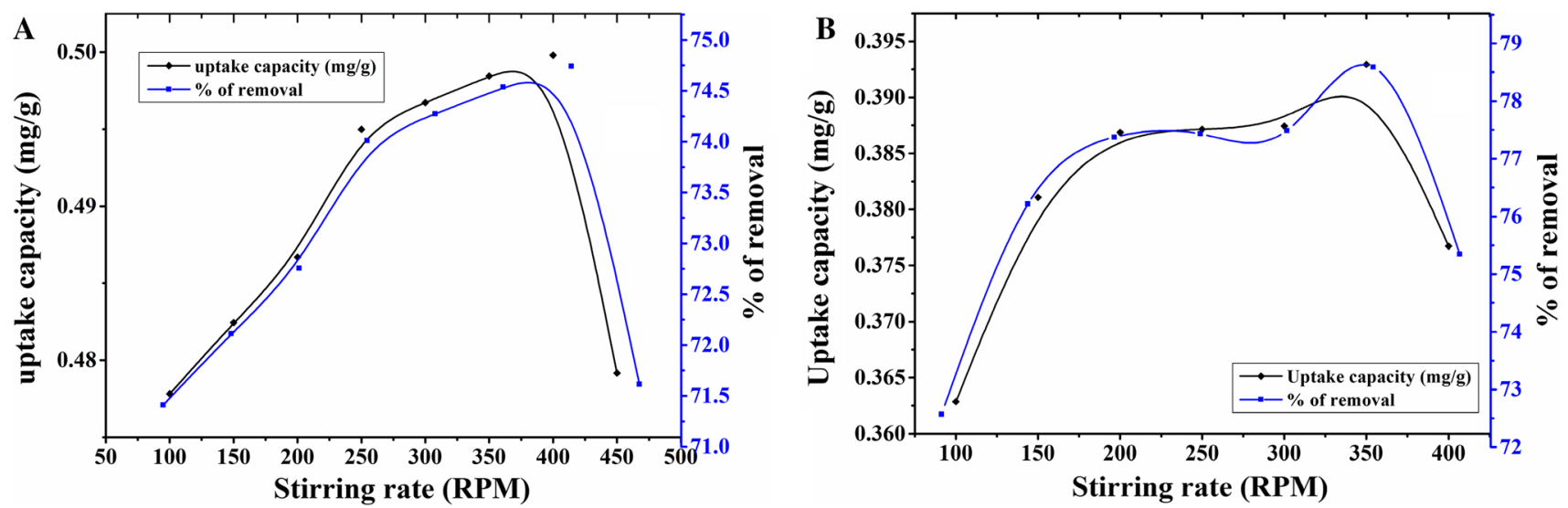

Fig. 9 Effect of stirring rate for arsenite (a) at $\mathrm{pH} 7,300 \mathrm{~K}$ temp, adsorbent dose $6 \mathrm{~g} / \mathrm{L}$, contact time $40 \mathrm{~min}$ and initial concentration $4 \mathrm{mg} / \mathrm{L}$. For arsenate (b) at $\mathrm{pH} 7,300 \mathrm{~K}$ temp, adsorbent dose $4 \mathrm{~g} / \mathrm{L}$, contact time $40 \mathrm{~min}$, and initial concentration $2 \mathrm{mg} / \mathrm{L}$
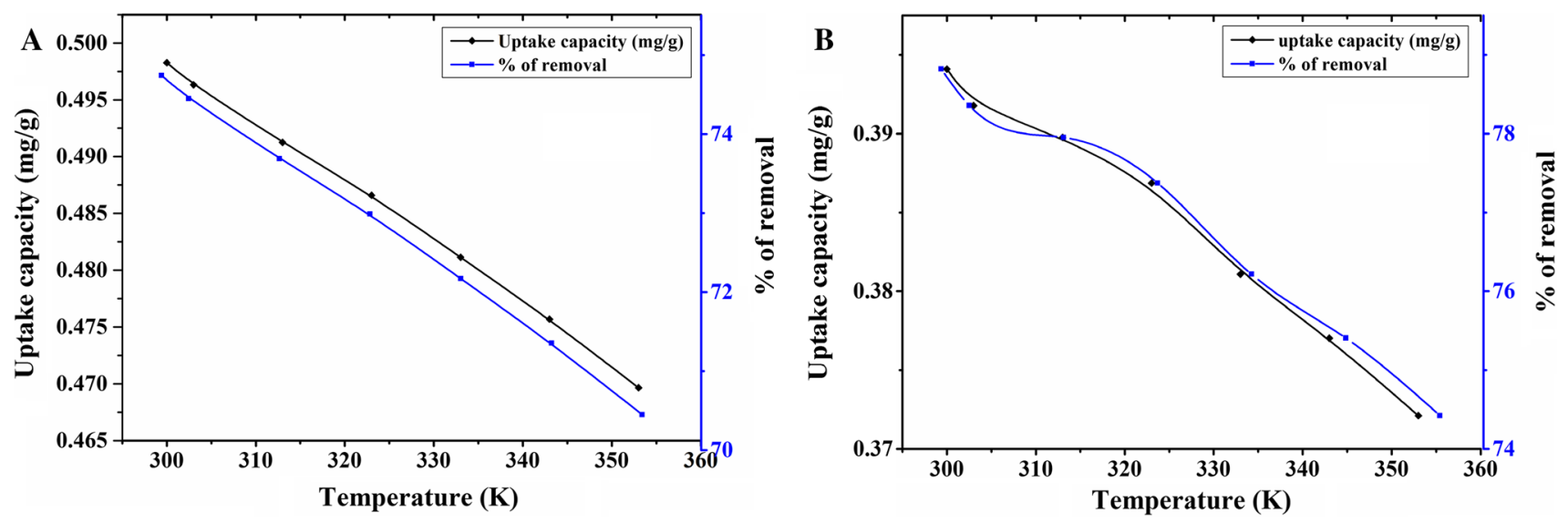

Fig. 10 Effect of temperature for arsenite (a) at pH 7, stirring rate $400 \mathrm{RPM}$, contact time $40 \mathrm{~min}$, adsorbent dose $6 \mathrm{~g} / \mathrm{L}$ and initial concentration $4 \mathrm{mg} / \mathrm{L}$. For arsenate (b) at $\mathrm{pH} 7$, stirring rate $350 \mathrm{RPM}$, contact time $40 \mathrm{~min}$, adsorbent dose $4 \mathrm{~g} / \mathrm{L}$, and initial concentration $2 \mathrm{mg} / \mathrm{L}$

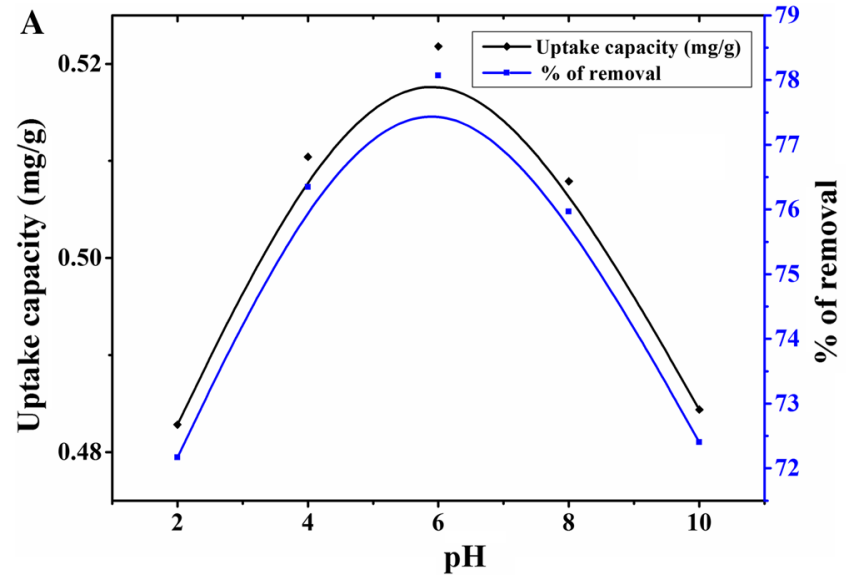

Fig. 11 Effect of $\mathrm{pH}$ for arsenite (a) at Initial concentration $4 \mathrm{mg} / \mathrm{L}$, adsorbent dose $6 \mathrm{~g} / \mathrm{L}$, contact time $40 \mathrm{~min}$, temperature $300 \mathrm{~K}$ and Stirring rate 400 RPM. For arsenate (b) at Initial concentration

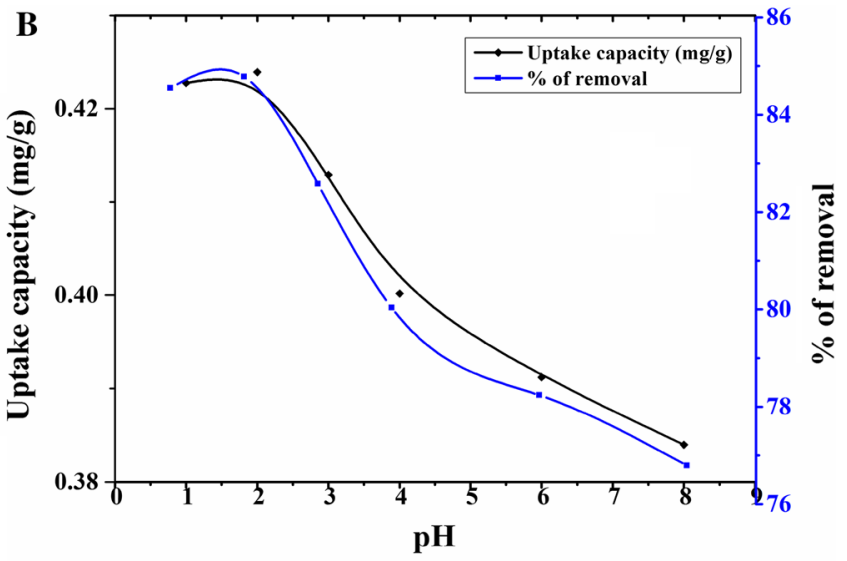

$2 \mathrm{mg} / \mathrm{L}$, adsorbent dose $4 \mathrm{~g} / \mathrm{L}$, contact time $40 \mathrm{~min}$, temperature $300 \mathrm{~K}$ and Stirring rate $350 \mathrm{RPM}$ 


\section{Adsorption isotherms}

Three different models, Dubinin-Radushkevich, Freundlich, and Langmuir, are commonly used to describe equilibrium sorption isotherms. In the present study, all three equations were examined to better understand the dominant As sorption mechanism operating at variant initial metal concentration $(0.5-5 \mathrm{mg} / \mathrm{L})$ and room temperature $(300 \mathrm{~K})$. Sorption data that best fit a Langmuir isotherm generally indicates that sorption is occurring on homogenous surface with a monolayer binding and no interaction between the sorbed molecules (Kundu and Gupta 2006a, b). The linear form of Langmuir equation is:

$C_{\mathrm{e}} / q_{\mathrm{e}}=1 / k q_{\mathrm{c}}+C_{\mathrm{e}} / q_{\mathrm{c}}$

where $C_{\mathrm{e}}$ is the final (equilibrium) concentration of metal in solution, $q_{\mathrm{e}}$ and $q_{\mathrm{c}}$ are the experimental and calculated uptake capacities of the adsorbent. The constant $k_{\mathrm{L}}$ is the Langmuir constant and $q_{\mathrm{c}}$ is calculated from the slope and intercept of the linearized Langmuir equation. In the present study, linear correlation coefficients $\left(R^{2}\right)$ for As (III) and As (V) for biosorption on to $C$. fistula were, respectively, 0.8071 and 0.505 (Table 1), indicating a poor fit to the Langmuir model. This suggest that the As adsorption study was not dominated by monolayer chemisorption. The maximum biosorption capacity $\left(q_{\mathrm{c}}\right)$ was $0.77 \mathrm{mg} / \mathrm{g}$ for As (III) and $1.01 \mathrm{mg} / \mathrm{g}$ for As (V). Current biosorption capacity was compared with other adsorbents studied earlier (Table 2).

When sorption data fit best the Freundlich isotherm, this indicates that adsorption is occurring on a heterogeneous surface with multilayer binding (Kundu and Gupta 2006a). The linear form of the Freundlich equation is:

$\log q_{\mathrm{e}}=\log K_{\mathrm{f}}+1 / n \log C_{\mathrm{e}}$

where $K_{\mathrm{f}}$ and $n$ are calculated from the slope and intercept of a plot of $\log \left(q_{\mathrm{e}}\right)$ verses $\log \left(C_{\mathrm{e}}\right)$ (Table 1). Relatively good correlation coefficient $\left(R^{2}\right)$ were found for both As (III) (0.9152) and As (V) (0.9601) suggesting the validity of this

Table 1 Isotherm (Langmuir, Freundlich, and Dubinin-Radushkevich) values

\begin{tabular}{llll}
\hline Isotherm & Model parameter & $\begin{array}{l}\text { Arsenic species } \\
\text { As }(\mathrm{III})\end{array}$ & $\begin{array}{l}\text { Arsenic species } \\
\text { As }(\mathrm{V})\end{array}$ \\
\hline Langmuir & $q_{\mathrm{c}}(\mathrm{mg} / \mathrm{g})$ & 0.7717 & 1.0088 \\
& $K_{\mathrm{L}}(\mathrm{L} / \mathrm{mg})$ & 0.3871 & 0.4928 \\
& $R^{2}$ & 0.8071 & 0.5051 \\
Freundlich & $K_{\mathrm{F}}(\mathrm{mg} / \mathrm{g})$ & 1.9897 & 1.065 \\
& $N$ & 0.5011 & 0.721 \\
& $R^{2}$ & 0.9152 & 0.9601 \\
Dubinin- & $\beta\left(\mathrm{mol}^{2} / \mathrm{J}^{2}\right)$ & $-3 \times 10^{-7}$ & $-1 \times 10^{-7}$ \\
Radushk- & $E\left(\mathrm{~kJ} / \mathrm{mol}^{2}\right)$ & 1.29 & 2.23 \\
evich & $R^{2}$ & 0.9693 & 0.9342 \\
\hline
\end{tabular}

model, implying multilayer adsorption on to heterogeneous surface. The maximum sorption capacity for arsenite and arsenate at $300 \mathrm{~K}$ was $1.9897 \mathrm{mg} / \mathrm{g}$ and $1.065 \mathrm{mg} / \mathrm{g}$, respectively.

The Dubinin-Radushkevich isotherm model is often used to identify the nature of the sorption as being either physical or chemical on heterogeneous surface (Namasivayam and Sureshkumar 2008). The linear form of the isotherm is:

$\ln \left(q_{\mathrm{e}}\right)=\ln \left(X_{\mathrm{m}}\right)-\beta F^{2}$

$F=R T \ln \left(1+1 / C_{\mathrm{e}}\right)$

where $q_{\mathrm{e}}$ is amount of adsorbate per unit of adsorbent and $C_{\mathrm{e}}$ is the amount of adsorbent in solution at equilibrium. The constant $\beta$ and $F^{2}$ are calculated from the slope and intercept of a plot of $\ln \left(q_{\mathrm{e}}\right)$ versus $F^{2}$. The mean energy of sorption $E$, which is defined as the free energy transfer from infinity to the surface of the sorbent for one mol. of solute, can be calculated using the calculated value of $\beta$ and:

$E=1 / \sqrt{-2 \beta}$

If $E<8 \mathrm{~kJ} / \mathrm{mol}$ physiosorption dominates, if $\mathrm{E}$ is between 8 and $16 \mathrm{~kJ} / \mathrm{mol}$ the mechanism is either chemisorption or ion-exchange, and if $E>16$, it indicates occurrence of only chemisorption (Mohan and Pittman 2006). For C. fistula As adsorption studies gave $E=1.29$ for As (III) and $E=2.23$ for As (V), indicating physiosorption of both species (Table 1). The correlation coefficients $\left(R^{2}\right)$ for the D-R isotherm model were also relative high being 0.9693 for As (III) and 0.9342 for As (V) indicating the D-R model was valid.

\section{Adsorption kinetics}

Three models (intraparticle diffusion, pseudo-first, and pseudo-second order models) were all used to describe the adsorption kinetics of As (III) and As (V) on to C. fistula. These kinetics models are generally used to investigate the reaction pathways and steps involved in adsorption. The pseudo-first-order equation is (Pokhrel and Viraraghavan 2007)

$\log \left(q_{\mathrm{e}}-q_{\mathrm{t}}\right)=\log q_{\mathrm{e}}-K_{1} t / 2.303$

where $q_{\mathrm{t}}$ is the change in uptake between adsorption phases. The pseudo-first-order reaction rate constant $K_{1}$ is calculated from the slope and intercept of plot of $\log \left(q_{\mathrm{e}}-q_{\mathrm{t}}\right)$ versus time $(t)$ (Table 3$)$. In the present study, correlation coefficients $\left(R^{2}\right)$ were 0.789 for As (III) and 0.696 for As (V), clearly indicating that pseudo-first-order equation was not followed. Consequently, the pseudo-second-order equation was investigated (Pokhrel and Viraraghavan 2007):

$t / q_{\mathrm{t}}=1 / K_{2} q_{\mathrm{e}}^{2}+t / q_{\mathrm{e}}$

$h=K_{2} q_{\mathrm{e}}^{2}$ 
Table 2 Comparison of uptake capacity, pH, initial concentration, and best-fitted isotherm model constants of As (III) and As (V) with other studied adsorbents

\begin{tabular}{|c|c|c|c|c|c|c|}
\hline Adsorbent & $\begin{array}{l}\text { Arsenic } \\
\text { species }\end{array}$ & $\mathrm{pH}$ & $\begin{array}{l}\text { Concentration range } \\
\text { of arsenic used }\end{array}$ & $\begin{array}{l}\text { Model used } \\
\text { to calculate } \\
\text { uptake } \\
\text { capacity }\end{array}$ & $\begin{array}{l}\text { Uptake } \\
\text { capacity } \\
(\mathrm{mg} / \mathrm{g})\end{array}$ & References \\
\hline \multirow[t]{2}{*}{ Activated Bauxsol } & As (III) & 4.5 & $2.04-156.7 \mathrm{mM}$ & Langmuir & 0.541 & Genc-Fuhrman et al. (2004) \\
\hline & As $(V)$ & & $7.03-220.9 \mathrm{mM}$ & & 7.642 & \\
\hline \multirow[t]{2}{*}{ Char carbon } & As (III) & $2-3$ & 193-992 mg/L & & 89.0 & Pattanayak et al. (2000) \\
\hline & As $(\mathrm{V})$ & & $157-737 \mathrm{mg} / \mathrm{L}$ & & 34.46 & \\
\hline Seawater-neutralized red mud & As $(\mathrm{V})$ & 7.3 & $0.80-32.00 \mathrm{mM}$ & Langmuir & 1.081 & Genc et al. (2003) \\
\hline Activated alumina & As (III) & 7.6 & $1 \mathrm{mg} / \mathrm{L}$ & Langmuir & 0.180 & Singh and Pant (2004) \\
\hline $\begin{array}{l}\text { Activated carbon }(\mathrm{AC}) \text { produced } \\
\text { from oat hulls }\end{array}$ & As $(V)$ & 5.0 & $25-200 \mu \mathrm{g} / \mathrm{L}$ & Langmuir & 3.08 & Chuang et al. (2005a, b) \\
\hline \multirow[t]{2}{*}{ Orange juice residue } & As (III) & $7-11$ & $15 \mathrm{mg} / \mathrm{L}$ & Langmuir & 70.43 & Ghimire et al. (2002) \\
\hline & As $(V)$ & $2-6$ & $15 \mathrm{mg} / \mathrm{L}$ & & 67.43 & \\
\hline Nanoscale zero-valent iron & As (III) & 7.0 & $1.0 \mathrm{mg} / \mathrm{L}$ & Langmuir & 2.47 & Kanel et al. (2005a, b) \\
\hline \multirow[t]{2}{*}{ Tea fungal biomass } & As (III) & 7.20 & $1.3 \mathrm{mg} / \mathrm{L}$ & Freundlich & 1.11 & Murugesan et al. (2006) \\
\hline & As $(\mathrm{V})$ & & $0.9 \mathrm{mg} / \mathrm{L}$ & & 4.95 & \\
\hline Activated alumina & As $(\mathrm{V})$ & 7.0 & & Langmuir & 9.20 & Takanashi et al. (2004) \\
\hline $\begin{array}{l}\text { Activated carbons from olive pulp } \\
\text { and olive stone }\end{array}$ & As (III) & 7.0 & $5-20 \mathrm{mg} / \mathrm{L}$ & Langmuir & 0.210 & Budinova et al. (2006) \\
\hline Coconut coir pith anion exchanger & As $(V)$ & 7.0 & $5.0-100 \mathrm{mg} / \mathrm{L}$ & Langmuir & 13.57 & Anirudhan and Unnithan (2007) \\
\hline Pine wood char & As (III) & 3.5 & $10-100 \mu \mathrm{g} / \mathrm{L}$ & Langmuir & 0.0012 & Mohan et al. (2007) \\
\hline Oak bark char & As (III) & 3.5 & $10-100 \mu \mathrm{g} / \mathrm{L}$ & Langmuir & 0.0074 & Mohan et al. (2007) \\
\hline \multirow[t]{2}{*}{ Cassia fistula pods' biochar } & As (III) & $2-10$ & $0.5-5 \mathrm{mg} / \mathrm{L}$ & Freundlich & 1.99 & Present study \\
\hline & As $(V)$ & & & & 1.07 & \\
\hline
\end{tabular}

where the pseudo-second-order reaction rate constant $K_{2}$ was calculated from the slope and intercept of plot $t / q_{\mathrm{t}}$ versus $t$ (Table 3$)$. Highly significant correlation coefficient $\left(R^{2}=1\right)$ for As (III) and ( $\left.R^{2}=0.9997\right)$ for As (V) were observed indicating almost perfect corroboration of a pseudo-secondorder sorption reaction where the rate of reaction depended directly on the square of the concentration of the reactants remaining in solution.

An intraparticle diffusion study was done to understand whether transport of the adsorbate into the pore of the adsorbent was possible as a rate-controlling step. The rate

Table 3 Kinetics (pseudo-first-order, pseudo-second-order, and intraparticle diffusion model) values

\begin{tabular}{llll}
\hline Kinetics & Parameter & \multicolumn{2}{l}{ Arsenic species } \\
\cline { 3 - 4 } & & As (III) & As (V) \\
\hline Pseudo-first order & $R^{2}$ & 0.789 & 0.696 \\
& $K_{1}$ & 0.066 & 0.0955 \\
Pseudo-second order & $R^{2}$ & 1 & 0.9997 \\
& $K_{2}$ & 18.19 & 6.855 \\
Intraparticle diffusion & $R^{2}$ & 0.8416 & 0.5482 \\
& $K_{\text {id }}(\mathrm{mg} / \mathrm{g} .0 .5 \mathrm{~min})$ & 0.0012 & 0.0027 \\
& $I$ & 0.7132 & 0.3781 \\
\hline
\end{tabular}

constant for intraparticle diffusion is calculated using the following equation (Lu et al. 2009).

$q_{\mathrm{t}}=K_{i} t^{0.5}+I$

where the value $k_{i}$ is calculated for both arsenite and $r$ arsenate at $300 \mathrm{~K}$ from the slope and intercept of plot of $q$ versus $1 / t$. Intercept of plot indicates the surface adsorption phenomenon occurring between the adsorbate and the adsorbent. The values of $K_{\mathrm{i}}$ and $I$ are given in Table 3. According to Ranjan et al. (2009), when the intercept line passes through the origin, it means intraparticle diffusion is the only rate-controlling step. However, in the present study, the intercept line does not pass through origin for either of the As species, which indicates that intraparticle diffusion is not the only rate-controlling step and that the mechanism of sorption by the adsorbent is more complex including both surface adsorption as well as intraparticle diffusion.

\section{Adsorption thermodynamics}

Determination of the free energy $\left(\Delta G^{\circ}\right)$ helps us to understand the spontaneity of any adsorption reaction. The free energy is calculated from two thermodynamic parameters, the heat of adsorption (enthalpy) $\left(\Delta H^{\circ}\right)$ and the standard 
Table 4 Thermodynamics study [free energy of adsorption $\left(\Delta G^{\circ}\right)$, the heat of adsorption (enthalpy) $\left(\Delta H^{\circ}\right)$, and standard entropy $\left(\Delta S^{\circ}\right)$ ] values

\begin{tabular}{|c|c|c|c|c|c|c|c|c|c|}
\hline \multirow[t]{2}{*}{ Arsenic species } & \multicolumn{7}{|c|}{$\Delta G^{\circ}(\mathrm{KJ} / \mathrm{mol})$} & \multirow[t]{2}{*}{$\Delta H^{\circ}(\mathrm{KJ} / \mathrm{mol})$} & \multirow[t]{2}{*}{$\Delta S^{\circ}(\mathrm{J} / \mathrm{mol} \mathrm{K})$} \\
\hline & $300 \mathrm{~K}$ & $303 \mathrm{~K}$ & $313 \mathrm{~K}$ & $323 \mathrm{~K}$ & $333 \mathrm{~K}$ & $343 \mathrm{~K}$ & $353 \mathrm{~K}$ & & \\
\hline As (III) & -2.711 & -2.703 & -2.677 & -2.651 & -2.624 & -2.598 & -2.571 & -3.503 & -2.640 \\
\hline As $(\mathrm{V})$ & -3.291 & -3.284 & -3.263 & -3.241 & -3.220 & -3.198 & -3.177 & -3.936 & -2.15 \\
\hline
\end{tabular}

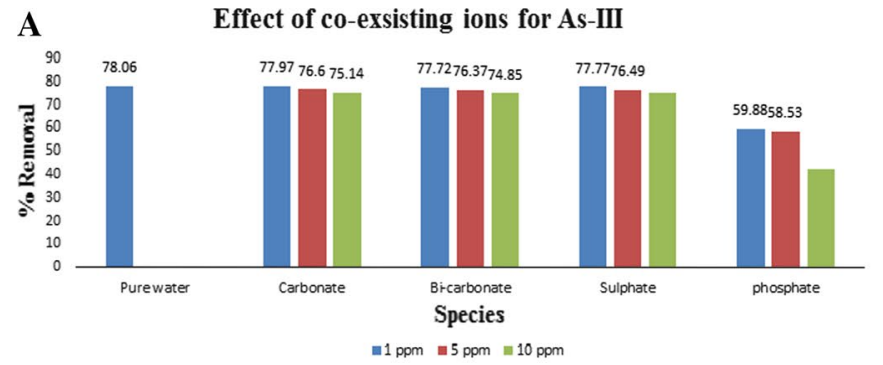

Fig. 12 a, b Effect of coexisting ions on As (III) \& As (V), respectively

entropy $\left(\Delta S^{\circ}\right)$, using the Gibbs free energy equation (Singh et al. 2006).

$\Delta G^{\circ}=-R T \ln K c$

The values of enthalpy $\left(\Delta H^{\circ}\right)$ and entropy $\left(\Delta S^{\circ}\right)$ are calculated by plotting $\ln K c$ versus $1 / T$, from the slope and intercept.

$K c=C A_{\mathrm{c}} / C_{\mathrm{e}}$

$\ln K c=-\Delta H^{\circ} / R T+\Delta S^{\circ} / R$

where $C A_{\mathrm{c}}$ is the amount of substance removed from solution in $\mathrm{mg} / \mathrm{L}$ and $C_{\mathrm{e}}$ is the final equilibrium concentration remaining in solution. The value $\Delta H^{\circ}$ and $\Delta S^{\circ}$ are calculated from the slope and intercept of plot of $\ln K c$ versus $1 / T$ (Table 4).

Since $\Delta G^{\circ}$ was negative for both As (III) $(-3.50)$ and As (V) (-3.94), this indicates that for both As species the adsorptive forces were sufficient to overcome the activation barrier energy relatively easily, and thus both sorption process were spontaneous. Likewise, $\Delta H^{\circ}$ was negative for both As species, indicating that sorption was exothermic. For both As species, $\Delta S^{\circ}$ was also negative indicating less degree of freedom for the adsorbate due sorption via association, fixation, or immobilization on the surface of the adsorbent (Ranjan et al. 2009).

\section{Effect of co-ions}

The effect of various common ions (carbonate, bicarbonate, phosphate, and sulfate) which were suspected of competing with As for adsorption binding sites was investigated using

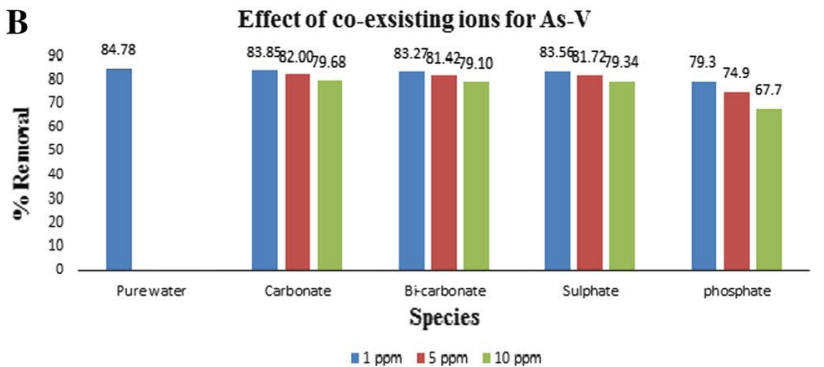

the earlier optimized experimental conditions for As sorption at effective ion concentrations of 1,5 , and $10 \mathrm{mg} / \mathrm{L}$. Phosphate showed the greatest effect while the other three anions exhibited only slight decreases in the adsorption efficiency. In general, removal efficiency decreased with increasing cation concentration with decreases in adsorption decreasing in the order of phosphate $>$ bicarbonate $>$ sulfate $>$ carbonate (Fig. 12a, b).

\section{Desorption study}

In assessing and adsorbent's potential for commercial applications the desorption efficiency is an important factor to consider. The desorption efficiency varied with the desorption agent used (Table 5), with the maximum regeneration being $23.1 \%$ for arsenite and $21.1 \%$ for arsenate when treated with $0.1 \mathrm{M}$ EDTA at $55{ }^{\circ} \mathrm{C}(328 \mathrm{~K})$. This indicated that the adsorbent was only slightly leachable. Leaching of arsenic will lead to potential groundwater contamination again.

Table 5 Regeneration study (using sodium hydroxide, nitric acid and EDTA)

\begin{tabular}{lll}
\hline Media & Species & \% of regeneration \\
\hline $\mathrm{NaOH}(0.1 \mathrm{M})$ & As (III) & 10.86 \\
& As (V) & 13.57 \\
$\mathrm{HNO}_{3}(0.1 \mathrm{M})$ & As (III) & 14.48 \\
& As (V) & 14.38 \\
EDTA $(0.1 \mathrm{M})$ & As (III) & 23.01 \\
& As (V) & 21.07 \\
\hline
\end{tabular}




\section{Conclusion}

From the observations of the present study, it can be concluded that activated biomass of $C$. fistula is a suitable adsorbent for removal of both arsenate and arsenite. Characteristics of the adsorbent like positive surface charge, the presence of suitable functional groups, and irregular heterogeneous surface morphology enhanced its adsorption potential considerably. Batch experiments proved optimum conditions for maximum removal efficiency as initial concentration of $4 \mathrm{mg} / \mathrm{L}$ for arsenite and $2 \mathrm{mg} / \mathrm{L}$ for arsenate, often encountered in natural water samples. Other environmental parameters for best removal conditions were contact time of $40 \mathrm{~min}$, a stirring rate of $400 \mathrm{RPM}$ for arsenite and $350 \mathrm{RPM}$ for arsenate and an adsorbent dose of $6 \mathrm{~g} / \mathrm{L}$ for arsenite and $4 \mathrm{~g} / \mathrm{L}$ for arsenate. Optimum temperature recorded was $27{ }^{\circ} \mathrm{C}$, which is normally the ambient mean temperature throughout the year in a tropical country like India. However, the optimum $\mathrm{pH}$ for adsorption was $\mathrm{pH}$ 6 for arsenite and $\mathrm{pH} 2$. This does not normally occur in the nature and hence has to be maintained artificially for application purpose. Moreover, it was also observed. While As sorption was significantly affected by the presence of phosphate, other common co-ions in natural waters (bicarbonate, carbonate, and sulfate had no significant effect on sorption. Thus, the presence of phosphate in natural water samples will decrease As removal efficiency of the adsorbent. Adsorbent regeneration was slightly favored by elevated temperatures.

Acknowledgements The authors would like to acknowledge the Department of Science and Technology, New Delhi for funding the SERB Young Scientist project SR/FTP/ES-2/2013 entitled "Arsenic enrichment in agricultural soils with potential impacts on crops and food security of Sahibganj, Jharkhand, India." The authors would also like to express their sincere thanks to Central Instrumentation facility, BIT, Mesra. The authors also greatly acknowledge the substantial inputs and suggestions provided by the anonymous reviewers (i.e., Professor Anna Mouse) who have undoubtedly significantly contributed to the improvement in this manuscript.

Open Access This article is distributed under the terms of the Creative Commons Attribution 4.0 International License (http://creativeco mmons.org/licenses/by/4.0/), which permits unrestricted use, distribution, and reproduction in any medium, provided you give appropriate credit to the original author(s) and the source, provide a link to the Creative Commons license, and indicate if changes were made.

\section{References}

Abbas M, Nadeem R, Zafar MN, Arshad M (2008) Biosorption of chromium (III) and chromium (VI) by untreated and pretreated Cassia fistula biomass from aqueous solutions. Water Air Soil Pollut 191:139-148
Ahmet S, Mustafa T (2010) Biosorption of As(III) and As(V) from aqueous solution by Lichen (Xanthoria parietina) biomass. Sep Sci Technol 45:463-471

Alam MO, Shaikh WA, Chakraborty S, Avishek K, Bhattacharya T (2016) Groundwater arsenic contamination and potential health risk assessment of Gangetic plains of Jharkhand, India. Expo Health 8:125-142

Anirudhan TS, Unnithan MR (2007) Arsenic(V) removal from aqueous solutions using an anion exchanger derived from coconut coir pith and its recovery. Chemosphere 66(1):60-66

Bhaumik R, Mondal NK, Das B, Roy P, Pal KC, Das C, Banerjee A, Datta JK (2012) Eggshell powder as an adsorbent for removal of fluoride from aqueous solution: equilibrium, kinetic and thermodynamic studies. E J Chem 9(3):1457-1480

Bortun A, Bortun M, Pardini J, Khainakov SA, Garcĺa JR (2010) Effect of competitive ions on the arsenic removal by mesoporous hydrous zirconium oxide from drinking water. Mater Res Bull 45:1628-1634

Budinova T, Petrov N, Razvigorova M, Parra J, Galiatsatou P (2006) Removal of arsenic(III) from aqueous solution by activated carbons prepared from solvent extracted olive pulp and olive stones. Ind Eng Chem Res 45:1896-1901

Bujňáková Z, Baláž P, Zorkovská A, Sayagués MJ, Kováč J, Timko M (2013) Arsenic sorption by nanocrystalline magnetite: an example of environmentally promising interface with geosphere. J Hazard Mater 262:1204-1212

Chakraborty S, Alam MO, Bhattacharya T, Singh YN (2014) Arsenic accumulation in food crops: a potential threat in Bengal delta plain. Water Qual Expo Health 6:233-246

Chammui Y, Sooksamiti P, Naksata W, Thiansem S, Arqueropanyo O (2014) Removal of arsenic from aqueous solution by adsorption on Leonardite. Chem Eng J 240:202-210

Chomchoey N, Bhongsuwan D, Bhongsuwan T (2013) Arsenic removal from synthetic wastewater by activated carbonemagnetic nanoparticles composite. In: Paper ID 93, international conference on mining, materials and petroleum engineering, November 11-13th, Chiang Mai

Choong TSY, Chuah TG, Robiah Y, Koay FLG, Azni I (2007) Arsenic toxicity, health hazards and removal techniques from water: an overview. Desalination 217:39-166

Chowdhury S, Mishra R, Saha P, Kushwaha P (2011) Adsorption thermodynamics, kinetics and isosteric heat of adsorption of malachite green onto chemically modified rice husk. Desalination 265:159-168

Chuang CL, Fan M, Xu M, Brown RC, Sung S, Saha B (2005a) Adsorption of arsenic (V) by activated carbon prepared from oat hulls. Chemosphere 61:478-483

Chuang CL, Fan M, Xu M, Brown RC, Sung S, Saha B, Huang CP (2005b) Adsorption of $\operatorname{arsenic}(\mathrm{V})$ by activated carbon prepared from oat hulls. Chemosphere 61(4):478-483

Das B, Mondal NK (2011) Calcareous soil as a new adsorbent to remove lead from aqueous solution: equilibrium, kinetic and thermodynamic study. Univers J Environ Res Technol $1: 515-530$

Du Y, Fan H, Wang L, Wang J, Wu J, Dai H (2013) One-pot, largescale synthesis of magnetic activated carbon nanotubes and their applications for arsenic removal. J Mater Chem A 1:7729-7737

Dupont L, Jolly G, Aplincourt M (2007) Arsenic adsorption on lignocellulosic substrate loaded with ferric ion. Environ Chem Lett 5:125-129

erÁansky S, Urík M, Ševc J, Khun M (2007) Biosorption and biovolatilization of arsenic by heat resistant fungi. Environ Sci Pollut Res 14(1):31-35

Fan X, Parker DJ, Smith MD (2003) Adsorption kinetics of fluoride on low cost materials. Water Res 37:4929-4937 
Fu D, Keech PG, Sun X, Wren JC (2011) Iron oxyhydroxide nanoparticles formed by forced hydrolysis: dependence of phase composition on solution concentration. Phys Chem Chem Phys 13:18523-18529

Genc H, Tjell JC, McConchie D, Schuiling O (2003) Adsorption of arsenate from water using neutralized red mud. J Colloid Interface Sci 264:327-334

Genc-Fuhrman H, Tjell JC, McConchie D (2004) Adsorption of arsenic from water using activated neutralized red mud. Environ Sci Technol 38(8):2428-2434

Ghimire KN, Inoue K, Makino K, Miyajima T (2002) Adsorption removal of arsenic using orange juice residue. Sep Sci Technol 37(12):2785-2799

Gimenez J, Martınez M, de Pablo J, Rovira M, Duro L (2007) Arsenic sorption onto natural hematite, magnetite, and goethite. J Hazard Mater 141:575-580

Guan X, Du J, Meng X, Sun Y, Sun B, Hu Q (2012) Application of titanium dioxide in arsenic removal from water: a review. J Hazard Mater 215:1-16

Hanif MA, Nadeem R, Bhatti HN, Ahmad NR, Ansari TM (2007) Ni (II) biosorption by Cassia fistula (Golden Shower) biomass. J Hazard Mater 139:345-355

Ishikawa SI, Sekine S, Miura N, Suyama K, Arihara K, Itoh M (2004) Removal of selenium and arsenic by animal biopolymer. Biol Trace Elem Res 102:113-127

Kanel SR, Manning B, Charlet L, Choi H (2005a) Removal of arsenic (III) from groundwater by nanoscale zero-valent iron. Environ Sci Technol 39:1291-1298

Kanel SR, Manning B, Charlet L, Choi H (2005b) Removal of arsenic(III) from groundwater by nanoscale zero-valent iron. Environ Sci Technol 39(5):1291-1298

Kanwal F, Rehman R, Mahmud T, Anwar J, Ilyas R (2012) Isothermal and thermodynamical modeling of Chromium (III) adsorption by composites of polyaniline with rice husk and saw dust. J Chil Chem Soc 57:1058-1063

Kumaresan M, Riyazuddin P (2001) Overview of speciation chemistry of arsenic. Curr Sci 80:837-846

Kundu S, Gupta AK (2006a) Arsenic adsorption onto iron oxidecoated cement (IOCC): regression analysis of equilibrium data with several isotherm models and their optimization. Chem Eng J 122:93-106

Kundu S, Gupta AK (2006b) Investigations on the adsorption efficiency of iron oxide coated cement (IOCC) towards As (V)kinetics, equilibrium and thermodynamic studies. Colloid Surf A 273:121-128

Kunzru S, Chaudhuri M (2005) Manganese amended activated alumina for adsorption/oxidation of arsenic. J Environ Eng 131:1350-1353

Lesmana SO, Febriana N, Soetaredjo FE, Sunarso J, Ismadjia S (2009) Studies on potential applications of biomass for the separation of heavy metals from water and wastewater. Biochem Eng J 44:19-41

Lu H, Luan M, Zhang J (2009) A kinetic study on the adsorption of chromium (VI) onto a natural material used as landfill liner. Electron J Geotech Eng 14:1-10

Mamindy-Pajany Y, Hurel C, Marmier N, Romeo M (2009) Arsenic adsorption onto hematite and goethite. C R Chim 12:876-881

Mandal S, Sahu MK, Patel RK (2013) Adsorption studies of arsenic(III) removal from water by zirconium polyacrylamide hybrid material (ZrPACM-43). Water Resour Ind 4:51-67

Markovski JS, Markovic DD, Dokic VR, Mitric M, Ristic MD, Onjia AE, Marinkovic AD (2014) Arsenate adsorption on waste eggshell modified by goethite, a- $\mathrm{MnO}_{2}$ and goethite/a- $\mathrm{MnO}_{2}$. Chem Eng J 237:430-442

Mohan D, Pittman CU Jr (2006) Activated carbons and low cost adsorbents for remediation of tri- and hexavalent chromium from water. J Hazard Mater 137(2):762-811
Mohan D, Pittman CU Jr, Bricka M, Smith F, Yancey B, Mohammad J, Steele PH, Alexandre-Franco MF, Serrano VG, Gong H (2007) Sorption of arsenic, cadmium, and lead by chars produced from fast pyrolysis of wood and bark during bio-oil production. J Colloid Interface Sci 310:57-73

Mondal MK (2010) Removal of $\mathrm{Pb}$ (II) from aqueous solution by adsorption using activated tea waste. Korean J Chem Eng 27:144-151

Murugesan GS, Sathishkumar M, Swaminathan K (2006) Arsenic removal from groundwater by pretreated waste tea fungal biomass. Bioresour Technol 97(3):483-487

Namasivayam C, Sureshkumar MV (2008) Removal of chromium (VI) from water and wastewater using surfactant modified coconut coir pith as a biosorbent. Bioresour Technol 99:2218-2225

Niu CH, Volesky B, Cleiman D (2007) Biosorption of arsenic (V) with acid-washed crab shells. Water Res 41(11):2473-2478

Ohki A, Nakayachigo K, Naka K, Maeda S (1996) Adsorption of inorganic and organic arsenic compounds by aluminium-loaded coral limestone. Appli Organomet Chem 10:747-752

Oke IA, Olarinoye NO, Adewusi SRA (2008) Adsorption kinetics for arsenic removal from aqueous solutions by untreated powdered eggshell. Adsorption 14:73-83

Pattanayak J, Mondal K, Mathew S, Lalvani SB (2000) A parametric evaluation of the removal of $\mathrm{As}(\mathrm{V})$ and $\mathrm{As}(\mathrm{III})$ by carbon based adsorbents. Carbon 38:589-596

Paul ML, Samuel J, Chandrasekaran N, Mukherjee A (2012) Comparative kinetics, equilibrium, thermodynamic and mechanistic studies on biosorption of hexavalent chromium by live and heat killed biomass of Acinetobacter junii VITSUKMW2, an indigenous chromite mine isolate. Chem Eng J 187:104-113

Pokhrel D, Viraraghavan T (2007) Arsenic removal froman aqueous solution by modified $A$. niger biomass: batch kinetic and isotherm studies. J Hazard Mater 150:818-825

Ranjan D, Talat M, Hasana SH (2009) Biosorption of arsenic from aqueous solution using agricultural residue 'rice polish'. J Hazard Mater 166:1050-1059

Ravenscroft P, Brammer H, Richards K (2009) Arsenic pollution: a global synthesis. Wiley-Blackwell, New York

Roy P, Mondal NK, Bhattacharya S, Das B, Das K (2013) Removal of arsenic(III) and arsenic(V) on chemically modified lowcost adsorbent: batch and column operations. Appl Water Sci 3:293-309

Schiewer S, Volesky B (2000) Biosorption process for heavy metal removal. In: Lovley DR (ed) Environmental microbe-metal interactions. ASM Press, Washington, pp 329-362

Senniappan S, Palanisamy S, Shanmugam S, Gobalsamy S (2017) Adsorption of $\mathrm{Pb}(\mathrm{II})$ from aqueous solution by Cassia fistula seed carbon: kinetics, equilibrium, and desorption studies. Environ Prog Sustain Energy 36(1):138-146

Singh TS, Pant KK (2004) Equilibrium, kinetics and thermodynamic studies for adsorption of As(III) on activated alumina. Sep Purif Technol 36:139-147

Singh KK, Singh AK, Hasan SH (2006) Low cost biosorbent wheat bran for the removal of cadmium from wastewater: kinetic and equilibrium studies. Bioresour Technol 97:994-1001

Sorokhaibam LG, Bhandari VM, Salvi MS, Jain S, Hadawale SD, Ranade VV (2015) Development of newer adsorbents: activated carbons derived from carbonized Cassia fistula. Ind Eng Chem Res 54:11844-11857

Suresh S, Srivastava VC, Mishra IM (2012) Adsorptive removal of aniline by granular activated carbon from aqueous solutions with catechol and resorcinol. Environ Technol 33:773-781

Takanashi H, Tanaka A, Nakajima T, Ohki A (2004) Arsenic removal from groundwater by a newly developed adsorbent. Water Sci Technol 50(8):23-32 
Tan X, Liu Y, Gu Y, Xu Y, Zeng G, Hu X, Liu S, Wang X, Liu S, Li J (2016) Biochar-based nano-composites for the decontamination of wastewater: a review. Bioresour Technol 212(2016):318-333

Tsai WT, Chen HR (2010) Removal of malachite green from aqueous solution using low-cost chlorella-based biomass. J Hazard Mater 175:844-849

Volesky B (2001) Detoxification of metal-bearing effluents: biosorption for the next century. Hydrometallurgy 59:203-216
WHO (1993) Guidelines for drinking-water quality, vol 1, 2nd edn. World Health Organization, Geneva

Zhang Y, Yang M, Huang X (2003) Arsenic (V) removal with a $\mathrm{Ce}(\mathrm{IV})$-doped iron oxide adsorbent. Chemosphere 51:945-952

Publisher's Note Springer Nature remains neutral with regard to jurisdictional claims in published maps and institutional affiliations 